\title{
Modelling Adoption of Innovation at a State Owned Company
}

\author{
Tamara Latifah Jasmine and Tatang Akhmad Taufik \\ Department Technology Management, Institut Teknologi Sepuluh Nopember, Surabaya \\ e-mail: tatang@mmt.its.ac.id
}

\begin{abstract}
This study aims To measure the level of technology readiness level (TRL) and to assess user acceptance to use the transportation management system software utilizing technology acceptance model (TAM) approach. Technology acceptance model (TAM) is used to describe the three components, i.e., perceived usefulness, perceived ease of use, and behavioral intention to use. To ensure that these 3 components are important factors of TAM, authors utilized factor analysis method, whereas t-test calculations were carried out to find out the relationships between components. The results show that the TRL of transportation management system software readiness is 9 which means that it is ready to be used widely in the company. The factor analysis shows that TAM is influenced by the three components, which is able to explain about $66.8 \%$ of variations. In the meantime the $t$ test shows that all hypotheses are accepted, so there are significant relationships between components analyzed. To summarize, the authors conclude that the company can benefit the usefulness and ease of use of the transportation management system software developed, so that the behavioral intention to use and the utilization of this technological innovation can be optimized.
\end{abstract}

Keywords-Transportation Management System Software, Technology Acceptance Models, Factor Analysis, t-test.

\section{INTRODUCTION}

$\mathrm{T}^{\mathrm{s}}$ ECHNOLOGY is one of the key factors in a company's competitiveness. This includes information and communication technology (ICT) and its innovation. Nevertheless, in order to make it effective and efficient, one needs to ensure its readiness to be adopted. On the other hand, good technology does not guaranteed that a value creation will result in an optimal way. Among other things, the company has to condition that the adopters also have readiness to accept and/or adopt the technological innovation.

This study was carried out to measure the technology readiness level (TRL) by adjusting and applying the TRL concept of NASA (see Taufik, 2005) at a state-owned logistics company. The company has developed a transportation management system application as an innovation introduced to a group of internal users in the company to support their operation of the clients' package distribution.

Furthemore, we analyzed the level of acceptance of the use of technology to be adopted. This study aims to find factors affecting the acceptance of technology uses. To do so, technology acceptance model (TAM) is utilized to explore the three main factors, i.e., Perceived Usefulness (PU), Perceived Ease of Use (PEOU) and Behavioral Intention to use (BI). A factor analysis and some statistical testings were performed.

\section{A. Technology Readiness Level}

Technology readiness level (TRL) is a system used to estimate technology maturity and was developed at the National Aeronautics and Space Administration (NASA) in the 1970 s as a standardized technology maturity assessment tool for use in complex system development [1]. TRL is based on a scale from 1 to 9 , with 9 being the most mature technology. These means that TRL of 1 is the least ready and 9 means that the technologyis already used in real-life conditions.

The NASA scale begins with a technology in its very basic scientific form and progresses to a technology proven in the required operating environment (Figure 1). Thus for a generic technology, the levels describe the demonstration requirements, including the environment and technology assembly status, gradually conforming to the final operating system as the design evolves. Figure 2 shows the scale of TRLs and transition phases.

In this study, TRL was measured using a software of "Teknometer ver. 2.5" developed by Badan Pengkajian dan Penerapan Teknologi (BPPT). This Microsoft Excel based software is a modified version of TRL Calculator ver. 2.2 developed by NASA. By filling in several standard questions related to the assessed technology, Teknometer will display the TRL graphically, and gives a snapshot of the status of the technology maturity/level.

\section{B. Technology Acceptance Model (TAM)}

The technology acceptance model (TAM) is a system acceptance model developed by Davis 1989, and is an adaptation of the Theory of Reasoned Action (TRA) model intoruced by Ajzen and Feishbein (1980). Derived from previous research which began with attitude and behavior theory, the emphasis of TRA at that time was on attitude from a psychological point of view.

The approach was developed to determine how to measure the relevant behavioral components of user's behavior, distinguish between beliefs or attitudes, and determine external stimuli. In the TRA model, the user's reaction and perception of the information system will determine the user's attitude and behavior. Subsequently in 1986 Davis conducted a dissertation research by adapting the TRA.

In 1989 Davis published the results of his dissertation research in MIS Quarterly, giving rise to the TAM theory with an emphasis on perceived ease of use and usefulness that 
The $6^{\text {th }}$ International Seminar on Science and Technology (ISST) 2020

July $25^{\text {th }}$ 2020, Institut Teknologi Sepuluh Nopember, Surabaya, Indonesia

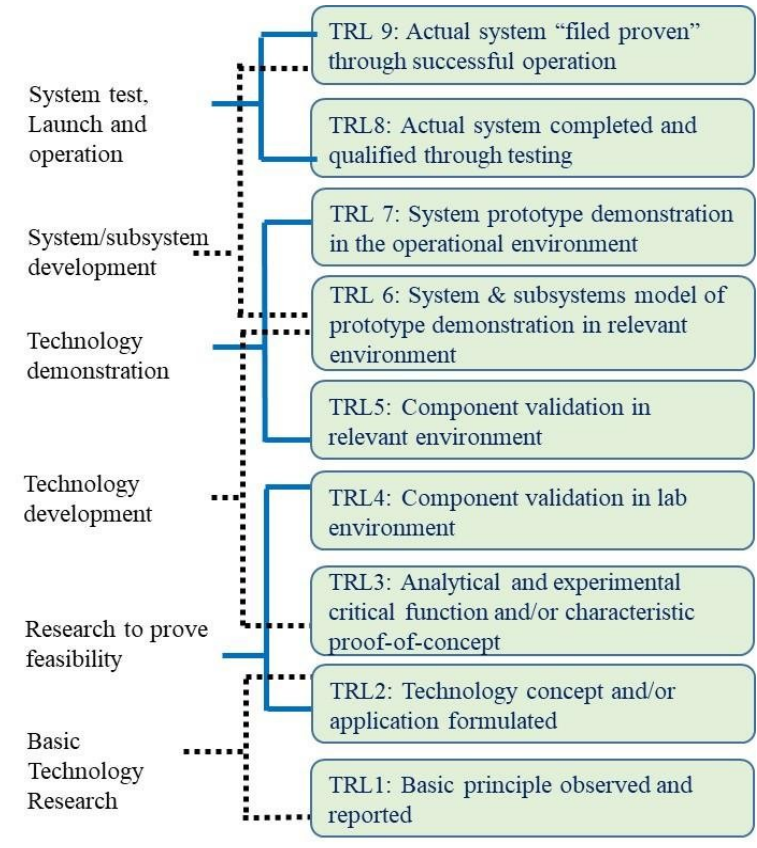

Figure 1. The Nasa Scale.

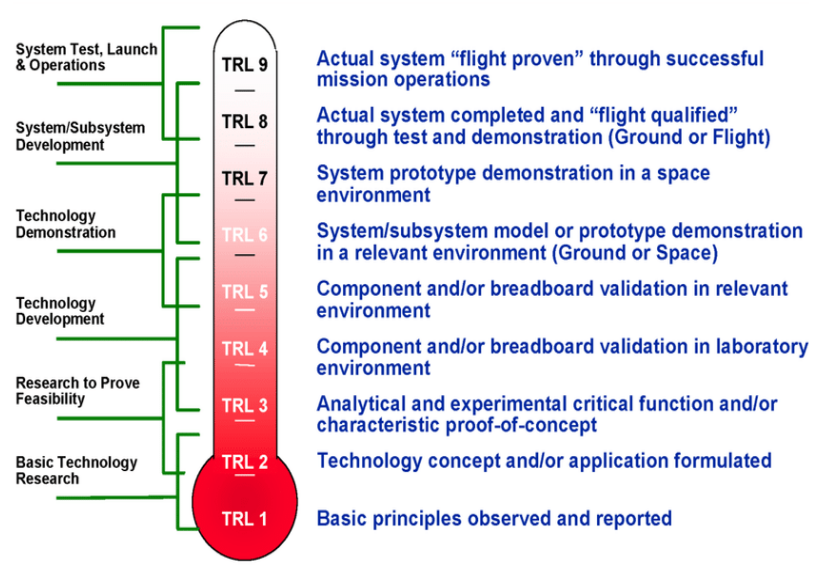

Figure 2. The Scale of TRL and Transition Phases.

show relationships to predict attitudes in using information systems. In its application, the TAM model is clearly much broader than the TRA model. These two factors that influence TAM are as the following:

\section{1) Perceived usefulness:}

Is defined as "the degree to which a person believes that using a particular system would enhance his or her job performance." This follows from the definition of the word useful: "capable of being used advantageously." Within an organizational context, people are generally reinforced for good performance by raises, promotions, bonuses, and other rewards [2]-[4]. A system high in perceived usefulness, in turn, is one for which a user believes in the existence of a positive use-performance relationship;

2) Perceived ease of use:

In contrast, refers to "the degree to which a person believes that using a particular system would be free of effort." This follows from the definition of "ease": "freedom from difficulty or great effort." Effort is a finite resource that a person may allocate to the various activities for which he or she is responsible.

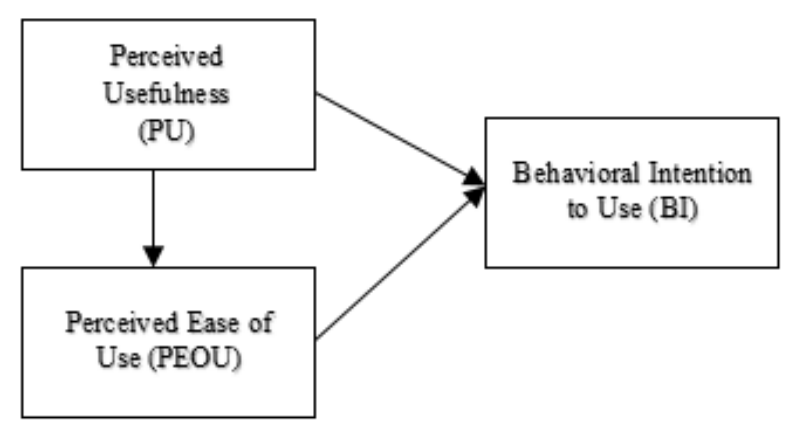

Figure 3. Original TAM Model.

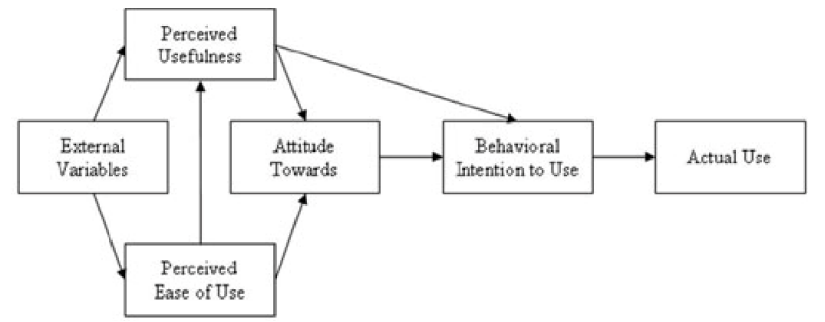

Figure 4. Proposed Model in This Study.

Table 1.

Result of Validity Test

\begin{tabular}{cccc}
\hline \hline Item & Value & r table & Valid/invalid \\
\hline PU1 & 0,521 & 0,266 & Valid \\
PU2 & 0,803 & 0,266 & Valid \\
PU3 & 0,247 & 0,266 & Valid \\
PU4 & 0,666 & 0,266 & Valid \\
PU5 & 0,555 & 0,266 & Valid \\
PEOU1 & 0,611 & 0,266 & Valid \\
PEOU2 & 0,755 & 0,266 & Valid \\
PEOU3 & 0,736 & 0,266 & Valid \\
PEOU4 & 0,558 & 0,266 & Valid \\
BI & 0,492 & 0,266 & Valid \\
\hline \hline
\end{tabular}

Correspondingly, Davis $(1986,1989)$ introduced the constructs in the original TAM (Figure 3) as follows: perceived usefulness (PU), perceived ease of use (PEOU), attitude, and behavioral intention to use. Among the constructs, PU and PEOU form an end-user's beliefs on a technology and therefore predict his or her attitude toward the technology, which in turn predicts its acceptance [5].

This study focused only on the three component TAM model, i.e., perceived usefulness (PU), perceived ease of use (PEOU) and behavioral intention to use (Figure 4).

\section{METHOD}

\section{A. Factor Analysis}

Factor analysis is used to recognize the basic dimensions or regularity of a phenomenon. The general purpose of factor analysis is to reduce a large amounts of variable information become a smaller factor variable [6]. Factor analysis is usually utilized in an explanatory research.

In addition, factor analysis can also be used to obtain a validity questionnaire series. Ghozali (2013) explained that 
The $6^{\text {th }}$ International Seminar on Science and Technology (ISST) 2020

July $25^{\text {th }} 2020$, Institut Teknologi Sepuluh Nopember, Surabaya, Indonesia

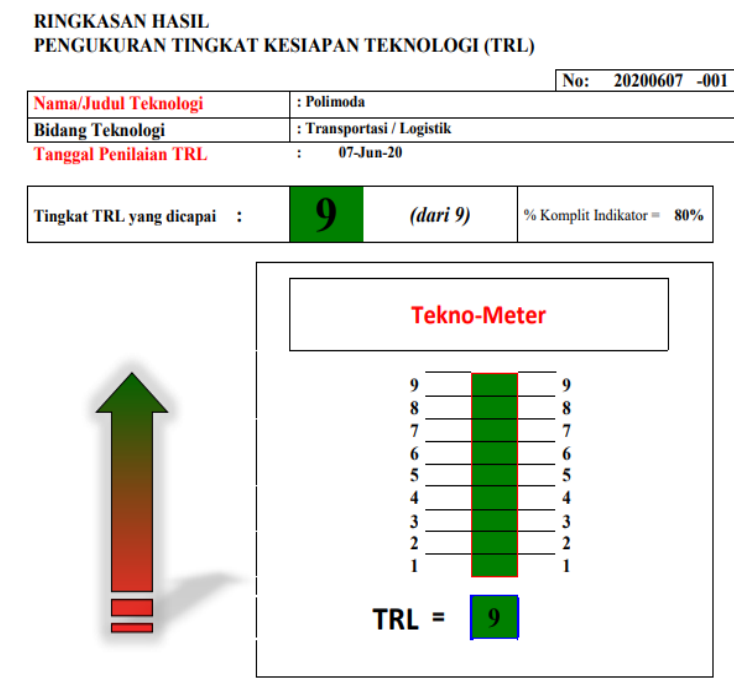

Figure 5. The Result of TRL.

Table 2.

Result of Reliability Test

\begin{tabular}{cc}
\hline Cronbach's Alpha & N of items \\
\hline 0.749 & 11 \\
\hline \hline
\end{tabular}

Table 3.

Result of KMO and Bartlett's Test

\begin{tabular}{ccr}
\hline Kaiser-Meyer-Olkin Measure of Sampling Adequacy. & 0.759 \\
\hline Bartlett's Test of Sphericity & Approx. Chi-Square & 196.608 \\
\cline { 2 - 3 } & df & 45 \\
\cline { 2 - 3 } & Sig. & 0 \\
\hline
\end{tabular}

Table 4.

Result of Measure Sampling Adequancy (MSA) Test.

\begin{tabular}{ccc}
\hline \hline Item & MSA Value & Standart \\
\hline PU1 & 0,776 & 0,5 \\
PU2 & 0,833 & 0,5 \\
PU3 & 0,599 & 0,5 \\
PU4 & 0,750 & 0,5 \\
PU5 & 0,703 & 0,5 \\
PEOU1 & 0,702 & 0,5 \\
PEOU2 & 0,827 & 0,5 \\
PEOU3 & 0,805 & 0,5 \\
PEOU4 & 0,665 & 0,5 \\
BI & 0,763 & 0,5 \\
\hline \hline
\end{tabular}

when he should consider the desired factor analysis, the data matrix must have sufficient analysis in order to be able to do the analysis factor. If based on visual data there is no value above 0.30 , then factor analysis cannot be done. Before doing a factor anysis, it is suggested to conduct a normality test. Normality test aims to determine the distribution of data in the variables to be used in the research. Decent and good data used in research is data that has a normal distribution. Normality test can use a normal test of kolmogorov-Smirnov. If $\mathrm{Sig}>0.005$ then the data is normally distributed, however if Sig $<0.005$ then the data are not normally distributed. Factor analysis can used in this situation :

1. Recognize or identify the underlying dimensions or factors, which explain the correlation between a set of variables.
Table 5.

Result of Extration Process

\begin{tabular}{ccc}
\hline Item & Nilai Ekstrasi & Keterangan \\
\hline PU1 & 0,439 & Lemah \\
PU2 & 0,722 & Kuat \\
PU3 & 0,729 & Kuat \\
PU4 & 0,698 & Kuat \\
PU5 & 0,732 & Kuat \\
PEOU1 & 0,746 & Kuat \\
PEOU2 & 0,700 & Kuat \\
PEOU3 & 0,747 & Kuat \\
PEOU4 & 0,813 & Kuat \\
BI & 0,357 & Lemah \\
\hline \hline
\end{tabular}

Table 6.

Factor That Formed

\begin{tabular}{cccc}
\hline \hline Total & \% of Variance & Cumulative \% & Formed \\
\hline 3,804 & 38,036 & 38,036 & Factors 1 \\
1,642 & 16,424 & 54,461 & Factors 2 \\
1,237 & 12,366 & 66,826 & Factors 3 \\
\hline \hline
\end{tabular}

Table 7.

Factoring Process.

\begin{tabular}{cccc}
\hline \hline & \multicolumn{3}{c}{ Component } \\
\cline { 2 - 4 } & $\mathbf{1}$ & $\mathbf{2}$ & $\mathbf{3}$ \\
\hline pu1 & 0.615 & 0.024 & 0.245 \\
pu2 & 0.403 & 0.631 & 0.401 \\
pu3 & -0.043 & 0.765 & -0.378 \\
pu4 & 0.797 & 0.248 & 0.018 \\
pu5 & 0.83 & 0.133 & -0.161 \\
peou1 & 0.179 & 0.069 & 0.842 \\
peou2 & 0.305 & 0.704 & 0.333 \\
peou3 & 0.241 & 0.779 & 0.286 \\
peou4 & -0.016 & 0.169 & 0.885 \\
bi & 0.546 & 0.16 & 0.181 \\
\hline \hline
\end{tabular}

2. Recognize and identify a new set of variables that are not correlated (independent) fewer in number to replace an original set which correlate with each other in multivariate analysis, such as multiple regression analysis and discriminant analysis.

Recognize or identify a set of variables that are important from a set of more variables in number to be used in the analysis next multivariate. The main process of factor analysis includes the following.

\section{1) Determinant of Correlation Matrix Test}

In the correlation matrix, interrelated variables are if the determinant value approaches 0 . The calculation results indicate the value of the Determinant Test of Correlation Matrix of 0.06 . This value approaches 0 , approaching correlation matrix between interrelated variables.

2) Kaiser Meyer Olkin Measure of Sampling (KMO)

Kaiser Meyer Olkin Measure of Sampling (KMO) is a comparison index of the distance between the correlation 
The $6^{\text {th }}$ International Seminar on Science and Technology (ISST) 2020

July $25^{\text {th }}$ 2020, Institut Teknologi Sepuluh Nopember, Surabaya, Indonesia

Table 8.

Result of T Test Between PU-PEOU

\begin{tabular}{lccccc}
\hline \hline \multirow{2}{*}{ Model } & \multicolumn{2}{c}{ Unstandardized Coefficients } & Standardized Coefficients & \multirow{2}{*}{ S } & Sig. \\
\cline { 2 - 5 } & $\mathrm{B}$ & Std. Error & Beta & & 1.376 \\
(Constant) & 0.728 & 0.529 & & 0.175 \\
PRCV.USEFULLNESS & 0.657 & 0.162 & 0.487 & 4.063 & 0 \\
\hline
\end{tabular}

a. Dependent Variable: PRCV.EASE OF USE

Table 9.

Result of T Test Between PU-BI

\begin{tabular}{|c|c|c|c|c|c|}
\hline \multirow{2}{*}{ Model } & \multicolumn{2}{|c|}{ Unstandardized Coefficients } & \multirow{2}{*}{$\frac{\text { Standardized Coefficients }}{\text { Beta }}$} & \multirow{2}{*}{$\mathrm{t}$} & \multirow{2}{*}{ Sig. } \\
\hline & $\mathrm{B}$ & Std. Error & & & \\
\hline (Constant) & 3.072 & 0.394 & & 7.79 & 0 \\
\hline PRCV.USEFULLNESS & 0.371 & 0.121 & 0.389 & 3.076 & 0.003 \\
\hline
\end{tabular}

a. Dependent Variable: BEHAVIORAL INTENTION

Table 10.

Result of T Test Between PEOU-BI

\begin{tabular}{|c|c|c|c|c|c|}
\hline \multirow{2}{*}{ Model } & \multicolumn{2}{|c|}{ Unstandardized Coefficients } & \multirow{2}{*}{$\frac{\text { Standardized Coefficients }}{\text { Beta }}$} & \multirow{2}{*}{$\mathrm{t}$} & \multirow{2}{*}{ Sig. } \\
\hline & B & Std. Error & & & \\
\hline (Constant) & 3.628 & 0.269 & & 13.49 & 0 \\
\hline PRCV.EASE OF USE & 0.226 & 0.092 & 0.32 & 2.455 & 0.017 \\
\hline
\end{tabular}

a. Dependent Variable: BEHAVIORAL INTENTION

coefficient and the partial correlation coefficient. If the amount squared partial correlation coefficient between all pairs of variables of small value when compared to the sum of the squares of the correlation coefficient, it will produce $\mathrm{KMO}$ values close to 1 . KMO value is considered sufficient if more than 0.5.

\section{3) Bartlett Test of Sphericity}

The Bartlett Test of Sphericity is a statistical test used for test the hypothesis that the variables are not mutually correlated population. Bartlett Test of Sphericity value is considered sufficient if more than 0.5

\section{4) Measure of Sampling Adequancy (MSA)}

In SPSS using the Kaiser Meyer Olkin index, so often called the Kaiser Meyyer (KMO) index used for researching the accuracy of the factor analysis by comparing the sample correlation coefficients which is observed by the partial correlation coefficient. Value (KMO MSA) up to 0.5-1.0 indicates that the analysis process carried out already right and can be continued [7]. In SPSS, a measure of sampling adequacy for each variable is displayed in each diagonal on the anti image correlation matrix. If the MSA size for a variable is small, then that variable need to be considered for elimination. KMO Test Criteria of the matrix between variables are as the following:

For $0.9<\mathrm{KMO} \leq 1.00$ the data is very good,

For $0.8<\mathrm{KMO} \leq 0.9$ the data is good

For $0.7<\mathrm{KMO} \leq 0.8$ data is good.

For $0.6<\mathrm{KMO} \leq 0.7$ the data is more than enough

For $0.5<\mathrm{KMO} \leq 0.6$ the data is sufficient

$\mathrm{KMO} \leq 0.5$ data is not feasible.

5) Extraction or factoring process

Factor extraction is a method used to reduce data from several indicators to produce fewer factors that can explain the correlation between the observed indicators. The methods used for doing factor extraction are principal component analysis, principal axis factoring, unweighted least squares, generalized least squares, and maximum likelihood.

6) Determine the Number of Factors

Determination the number of factors is based on the magnitude of the eigen value of each emerging factor. Eigen value is the number of variations explained by each factor. The result is to do a factor analysis to find new variables socalled fewer correlated factors, free of each other, the number is than the original variable, but can absorb some of the information contained in the original variable. The core factors chosen are the factors has an eigen value $>1$.

7) Factors Rotation

Factor rotation is used to facilitate interpretation in determining which variables are included in a factor because sometimes, there are several variables that have a high correlation with more than one factor or if the loading factor of a variable is below the smallest value set. An important outcome or output in factor analysis is what is called a factor pattern matrix. Load/ contain factor matrix coefficients used to express standardized variables stated in factors.

The results of the factor extraction have no meaning if they are not rotated because extraction rotation is useful for enabling scientific interpretation and review. Factor analysis has two rotations, orthogonal rotation and oblique rotation. Parts of orthogonal rotation are varimax, quartimax, and equamax [8]. In this study, used varimax rotation. Varimax rotation is one type of orthogonal rotation (available in SPSS). The main purpose of this method is to get a factor structure so that each variable is loaded only on a certain height factor. So, each variable must have a high charge on one factor and zero on other factors. 
The $6^{\text {th }}$ International Seminar on Science and Technology (ISST) 2020

July $25^{\text {th }} 2020$, Institut Teknologi Sepuluh Nopember, Surabaya, Indonesia

\section{B. Validity Test}

According to Sugiyono (2017), validity shows the degree of accuracy between real data occurs in objects with data collected by the researcher. To find the validity of an item, we correlate item scores with total of these items. Research items will be considered valid if the value of $r$ count $>r$ table using a 5\% significance level (95\% confidence level). On this studywith the number of respondents is 55 , the value of $r$ table must be $\geq 0.266$.

\section{Reliability test}

Reliability is a tool to measure a questionnaire which is indicator of a variable or construct. Reliability shows consistency and stability of a score (measurement scale). A questionnaire is said to be reliable if a person's answer to a question is consistent or stable from time to time [9]. The reliability value is expressed by Cronbach's Alpha coefficient based the lowest limit of reliability criteria is 0.6.

\section{D. $\quad$ test}

There are two types of statistical inference: parametric and nonparametric methods. Parametric methods refer to a statistical technique in which one defines the probability distribution of probability variables and makes inferences about the parameters of the distribution. In cases in which the probability distribution cannot be defined, nonparametric methods are employed. T-tests are a type of parametric method, they can be used when the samples satisfy the conditions of normality, equal variance, and independence.

T-test is used to test partially the regression coefficient. This test is conducted to determine the significance of the partial role between independent variable to the dependent variable by assuming that other independent variables are considered constant. The results of calculation, will compared with $t$ tables using an error rate of 0.05 . The criteria used are as follows:

- $\mathrm{H}_{0}$ is accepted if the value of $\mathrm{t}$-calculate $\leq \mathrm{t}$ table or $\mathrm{sig}>$ $\alpha$ value. This means that there is no significant effect of one independent variable on the dependent variable.

- $\mathrm{H}_{0}$ is rejected if the value of $\mathrm{t}$-calculate $\leq \mathrm{t}$ table or $\mathrm{sig}<\alpha$ value. This means that there is a significant influence of one independent variable on the dependent variable.

\section{RESULTS AND DISCUSSION}

Figure 5 shows that the results of The TRL measurement of the transportation management system software is at level 9. This means the software is ready to be applied across the company.

For the validity test, Table 1 shows that 10 items in TAM variable, has a validity value (larger than $r$ table, which is $>$ 0.266). This means all items in TAM variable are valid and can be used for the next testing phase. The data will be used in factor analysis. Table 2 shows that the overall TAM reliability value in this research is 0.749 (larger than $r$ table, which is $>0.6$ ). It means that the model is reliable.

The KMO and Bartlett's Test in Table 3 shows a KMO value is 0.759 or more than 0.50 it mean that items are considered to be correlated with each other, so items on this
TAM variable can be used in the next factor analysis process. Then Table 4 indicates that the Measure of Sampling Adequancy value of the item on the TAM variable is more than 0.5. This means that requirements of this test is fulfilled. The items used in this factor analysis are items that have passed the elimination stage in the validity test conducted previously. In other words, the second requirement for the factor analysis has been fulfilled and can proceed to the next step.

The process of extraction or factoring is the process of separating variables correlating with the MSA value. A variable is correlated, if the MSA value is greater than 0.5 . The number of variables to be extracted is shown in Table 5 and explain the correlation value of items to the factors that will be formed. The greater the extraction value, the greater or stronger the contribution of the items to explain the TAM variable. There are two items PU1 and BI which has an extraction values more than 0.50 , so this item is considered weak to explain the TAM variable. After process of extration done, the next step in factor analysis is factoring process.

Factoring process in Table 6 shows that of 10 items in the TAM variable in this study. It was formed into 3 factors, the formation of factors is according to the initial eigen values requirements that must be more than 1 . In factor 1 can be seen that the eigenvalue is 3.804 which means $>1$, factor 1 can explain $38.036 \%$ or $38 \%$ of variation; factor 2 has an eigenvalue of 1.642 and can explain $16.4 \%$ variation; and factor 3 has an eigenvalue of 1.237 and can explain $12.4 \%$. When factors 1 , factor 2 and factor 3 are combined, the whole is able to explain $66.8 \%$ of the variation in the TAM model.

The last step in factor analysis is grouping the items to factors formed. As shown in Table 7, the grouping of the items are the following:

1. Factor 1 is formed by items pu1, pu4, pu5, bi

2. Factor 2 is formed by items pu2, pu3, peou2, peou3

3. Factor 3 is formed by items peou1, peou 4

The analysis result above, there are 3 forming factors in TAM model, where these 3 factors are formed with items perceived of usefulness, perceived ease of use and behavioral intention that are able to explain $66.8 \%$ variations, so the results of factor analysis are suitable according to the opinion of Davis et al (1989) that in the TAM 1 or TAM original is influnced by perceived of usefulness, perceived ease of use and behavioral intention and two others.

$\mathrm{T}$ test in this study is used to test the hypothesis are as follow:

H1: There is a significant relationship between perceived of usefulness (PU) with perceived ease of use (PEOU)

Table 8 shows that the $\mathrm{t}$-value is 4.063 , it means greater than the t-table value (2.005) and a significance value is 0.000 or less than 0.05 . H0 then is rejected and there is a significant relationship between perceived of usefulness (PU) with the perception of ease use (PEOU).

H2: There is a significant relationship between perceived of usefulness (PU) and behavior intention to use (BI)

Table 9 shows that the t-value is 3.076. It means greater than the t-table value (2.005) and a significance value is 0.003 or less than 0.05 , then $\mathrm{H} 0$ is rejected and there is a significant 
relationship between the variable perceived of usefulness (PU) with the behavior intentions to use (BI).

H3: There is a significant relationship between perceived ease of use (PEOU) variables and behavior intentions to use (BI)

Table 10 shows that the t-value is 2.445 . This means greater than the t-table value (2.005) and a significance value is 0.017 or less than 0.05 . In other words, H0 is rejected and there is a significant relationship between the variable perceived ease of use (PEOU) and behavior intentions to use (BI).

\section{CONCLUSION}

The result shows that the readiness level of the transportation management system software is at level 9, meaning that it has been proven for successful operations across the company.

Factor analysis carried out in this research shows that the model matches the concept of Davis et al (1989), that is the TAM 1 or the "original" TAM. This original version underlie that behavioral intention is influenced by perceived of usefulness and perceived ease of use.

The t-tests show that all alternative hypothesis are accepted with a value is larger than $\mathrm{t}$ table $(2,005)$. So there are significant relationships among components in TAM variables. To summarize, we conclude that the company can benefit the usefulness and ease of use of the transportation management system software developed as a good innovation, so that the behavioral intention to use and the utilization of this technological innovation can be optimized.

\section{REFERENCES}

[1] T. A. Taufik, "Konsep dan metode pengukuran Tingkat Kesiapan Teknologi/TKT (Technology Readiness Level/TRL)," 2005.

[2] J. Pfeffer, Organizations and Organization Theory. Boston, Massachusetts: Pitman Books Ltd, 1982.

[3] E. H. Schein, Organizational Psychology. Englewood Cliffs, New Jersey: Prentice-Hall, 1980.

[4] V. H. Vroom, Work and Motivation. New York: Wiley, 1964.

[5] F. D. Davis, R. P. Bagozzi, and P. R. Warshaw, "A Comparison of Two Theoretical Models. Management Science," J. Manag. Sci., vol. 35 , no. 8, pp. 982-1003, 1989, doi: 10.1287/mnsc.35.8.982.

[6] M. Kuncoro, Metode Riset untuk Bisnis dan Ekonomi. Jakarta, Indonesia: Erlangga, 2009.

[7] M. J. Norusis, SPSS/PC+: Advanced Statistics : for The IBM $P C / X T / A T$. Chicago, Illinois: SPSS Inc, 1986.

[8] R. A. Johnson and D. W. Winchern, Applied Multivariate Statistical Analysis, 6th ed. New Jersey: Pearson Prentice Hall, 2007

[9] S. Sugiyono, Metode Penelitian Bisnis: Pendekatan Kuantitatif, Kualitatif, Kombinasi, dan R\&D. Bandung, Indonesia: CV. Alfabeta, 2017. 